\title{
INTERNATIONAL TRANSMISSION OF MONETARY POLICY: THE USA TO INDIA
}

\author{
Anuradha Patnaik \\ Assistant Professor Department of Economics \\ University of Mumbai, Mumbai-98 \\ E-mail address: apatnaik@economics.mu.ac.in
}

\begin{abstract}
Keywords: Exchange rates; Volatility Spillover; Multivariate GARCH models; Dynamic Conditional Correlations
\end{abstract}

\begin{abstract}
The present study attempts measure the transmission of monetary impulse from the USA to India by trying to quantify the extent of volatility spillover from the US monetary policy to the exchange rate and interest rate of India. By applying a t-DCC MGARCH model to daily data on Fed Funds Rate, Rupee Dollar Exchange Rate and the Call Money rate of India it was found that there is considerable volatility spillover from the Fed Rate to the exchange rate. Spillover is also clearly evident in case of the call rate. The extent of spillover is higher for the foreign exchange rate than the call money rate. However, it was also noticed that the spillover is asymmetric in either of the cases and is higher during phases of high volatility. In an era of flexible exchange rates excessive dependence of the Indian Economy on short term capital flows to finance the current account deficits which raises the dollar demand and exposes the Indian economy to the Monetary Policy of the US, needs to be reduced. Reforms in the nature of capital flows is also the need of the hour.
\end{abstract}

\section{INTRODUCTION}

The Indian Rupee depreciates or appreciates subsequent to every monetary policy announcement of the Federal Reserve Bank of USA. One such process of depreciation of the rupee was triggered by the news of roll back of Quantitative Easing Program by the Governor of Federal Reserve Bank of USA, in the second and third quarter of 2013. This imparted considerable volatility in the exchange rate market and other asset prices markets in India. Notwithstanding the calibrated move of India towards an open capital accounts, the short term capital flows away from India engendered the volatility in the markets. Needless to mention that integration of domestic markets resulted in cross spillover of volatility across all markets. The USA intends to hike the Fed rate, towards the end of this year, due to which the IMF has warned the USA to postpone contractionary monetary policy (or rate hike) till 2016. The present paper therefore attempts to estimate the extent of volatility spill over from the US to India, through the exchange rate and interest rates using t-DCC-MGARCH (Dynamic Conditional Correlations Multivariate GARCH) model. The Rest of the paper is organised as follows:- Section II Reviews the Literature, In Section III the data and Metodology have been outlined. The Results of Empirical Analysis are discussed in Section IV and Section V Concludes.

\section{REVIEW OF LITERATURE:}

In the last two decades volatility and volatility spillover across assets have been studied intensively both at international as well as domestic level. These studies differ on, the choice of assets, domestic spillovers, international spillovers and methodological issues.

Different variants of Multivariate GARCH have become standard tools to model volatility in a multivariate framework, ever since the introduction of half vec form of Multivariate GARCH model by Bollerslev, Engle and Wooldrige (1988). The BEKK formulation of Engle and Kroner (1995), factor GARCH model of Engle, $\mathrm{Ng}$ and Rothschild (1990), Alexander (2000), etc were distinct 
modifications and upgradations to the original MV GARCH model. Engle (2001), proposed the Dynamic Conditional Correlations (DCC) model which preserves the parsimony of univariate GARCH models of individual assets volatility with simple GARCH like time varying correlations (Engle and Sheppard, 2001). Further extensions to Engle's DCC model can be found in Kearney \& Poti (2003), Pelagatti \& Roudena (2004), Lee, Shiou \& Lin (2006) Billio, Caporin \& Gobbo (2003, $2006)$ etc. However, the most significant improvement to the DCC model of Engle (2001), was made by Pesaran and Pesaran,(2007), who modified the DCC model for multivariate $t$ distribution of returns. The DCC models have been used to study volatility spillover extensively (Dijt, Munandar and Hafner (2005), Hautschand and Inkman (2003), Baurista, (2003)).

Some of the studies on volatility in the Indian context are those of Badrinath and Apte (2005), Mishra and Paul (2008), Mishra, Swain and Malhotra (2007), Batchelor and Dua, (2003). While these studies differ considerably in the methodological aspects and the choice of assets, asymmetric volatility spillovers and volatility clustering have been found in all the cases.

\section{METHODOLOGY AND DATA}

\subsection{The DCC model of Engle (2002) and t-DCC model of Pesaran and Pesaran (2007)}

The different variants of the MGARCH models differ in terms of the way the variance covariance matrix of the variance equation of the returns vector is decomposed.

\subsubsection{The Engle Model}

Engle's (2002), k-vector of assets is conditionally multivariate normal as given in equation (1).

$r_{t} / \Phi_{t-1} \backsim N\left(0, H_{t}\right)$

Each element of the k-vector of the asset returns is modeled as follows:-

$$
r_{i t}=\mu+u_{i t}
$$

From the residuals of equation (2), the conditional variances of each asset return is derived using the equation (3) given below.

$h_{i t}^{2}=\omega_{i}+\Sigma \alpha_{p i} u_{i t}^{2}+\Sigma \beta_{q i} h_{i t-q}^{2}$

Where $\Sigma \alpha_{\mathrm{pi}}+\Sigma \beta_{q i}<0$

Where

$$
H_{t}=D_{t} R_{t} D_{t}
$$

(1) $H_{t}$ is the Conditional Covariance matrix of $r_{t}$

(2) $D_{t}$ is the $\mathrm{k} \mathrm{x} \mathrm{k} \mathrm{diagonal} \mathrm{matrix} \mathrm{of} \mathrm{time} \mathrm{varying} \mathrm{standard} \mathrm{deviations} \mathrm{obtained} \mathrm{from} \mathrm{the}$ univariate GARCH specifications given in equation (3)

(3) $R_{t}$ is the $\mathrm{k} \mathrm{x} \mathrm{k} \mathrm{time} \mathrm{varying} \mathrm{correlations} \mathrm{matrix.} \mathrm{It} \mathrm{is} \mathrm{derived} \mathrm{by} \mathrm{first} \mathrm{standardizing} \mathrm{the}$ residuals of the mean equation (2) of the univariate GARCH model with their conditional standard deviations derived from equation (3) to derive $\eta_{i t}$. Thus

$\eta_{\text {it }}=u_{i t} / \sqrt{h_{i t}^{2}}$

These standardized residuals are then used to estimate the parameters of conditional correlation as given in equation (6) below.

$$
\begin{aligned}
& \qquad R_{t}=\left(\operatorname{diag}\left(Q_{t}\right)\right)^{-1 / 2} Q_{t}\left(\left(\operatorname{diag}\left(Q_{t}\right)\right)^{-1 / 2}\right. \\
& \text { And } \\
& Q_{t}=\left(1-\alpha_{i}-\beta_{i}\right) Q+\alpha_{i} \eta_{i t-1} \eta_{i t-1}^{\prime}+\beta_{i} Q_{t-1}
\end{aligned}
$$

Where $\bar{Q}$ is the unconditional covariance of the standardized residuals. The $Q_{t}$ does not generally have ones on the diagonal, so it is scaled as equation (7) above, to derive $R_{t}$, which is a positive definite matrix. In this model the conditional correlations are thus dynamic or time varying. 


\subsubsection{Pesaran \& Pesaran's Model}

It has been observed that the return series might not be Gaussian, and so in order to capture the 'fat tailed nature of the asset returns' Pesaran and Pesaran (2007) have combined the DCC model with a multivariate $t$ distribution. They estimate the dynamic conditional correlations matrix $\mathrm{R}$ using the devolatised returns instead of standardised returns. The difference between the two being that while in case of the devolatised returns standardisation is done using realised volatility, in the standardised returns of Engle, the standardisation is done using the GARCH type of conditional volatility. The devolatised returns are likely to be approximately Gaussian although the same cannot be said about the standardised volatility.

\subsubsection{Diagnostic Testing of the $t$ DCC model}

The model efficacy test can be conducted using the Berkowitz (2001) test which is based on the probability of integral transforms. Under the null hypothesis of correct specification of the $t$ DCC model, the probability transform estimates are serially uncorrelated can be tested using the Lagrange Multiplier test. The probability integral transform variables have to be serially uncorrelated and uniformly distributed over the range $(0,1)$. Here the LM statistics has to be insignificant

\subsection{Data and Variables Used}

1) Effective Federal Fund Rate :-Effective Federal Fund Rate which is the interest rate at which depository institutions trade federal funds (balances held at Federal Reserve Banks) with each other overnight. The rate that the borrowing institution pays to the lending institution is determined between the two banks; the weighted average rate for all of these types of negotiations is called the effective federal funds rate. This rate is determined by the market but is influenced by the Federal Reserve through open market operations (OMO) to reach the federal funds rate target. Since the Fed Fund Rate is significantly influenced by the OMO of the Federal Reserve, it is more or less an indicator of the monetary policy of the US. Also since it is market determined, it is volatile. The present study aims to construe the volatility spill over on the exchange rate and interest rate of India due to the monetary policy of the US in an MGARCH framework. Hence the choice of this variable.

2) Call Money Rate of India:- The call money rate is the market determined short term interest rate of India. Since it is market determined it has been used in the present study to identify the spillover of volatility from the Fed Fund Rate.

3) Rupee Dollar Exchange Rate:- The rupee dollar exchange rate is also market determined. Since it is market determined it has been used to identify the spillover of volatility from the Fed Fund Rate.

Daily data on all the above variable has been used for the period 20 ${ }^{\text {th }}$ April 2013 to 14 Sept 2013. The data on Fed Fund Rate was collected from the following FRB of St. Louis website:http://research.stlouisfed.org/fred2/data/DFF.txt. Data on Call Money rate and Rupee dollar Exchange rate was collected from various issues of RBI Monthly Bulletins. The present study employs the MGARCH t DCC model as introduced by Engle (2002) and modified by Pesaran and Pesaran (2007).

Considering the depreciation of the Indian rupee post the announcement of rollback of the Quantitative Easing (QE) program by the Governor of Federal Reserve Bank of US, it is hypothised that there has been a volatility spillover from the US to India. Since all asset prices are linked we look into the volatility spillover into the interest rate of India also.

\subsection{Steps of Empirical Analysis}

1) Constructing the return series of all the three variables used in the empirical analysis. The simple growth rate of each of the variables was used as the return from the assets.

2) Estimating the descriptive statistics. 
3) Stationarity test of all the return series

4) Estimation of the MGARCH DCC model

5) Diagnostic testing of the MGARCH DCC model

\section{RESULTS OF EMPIRICAL ANALYSIS}

Step I

All the three variables were converted into growth rates to derive the returns on each asset price.

Step II

The descriptive statistics of the three return series were estimated and have been reported in table 1 below. It is clear from the table 1 above that none of the return series follow a normal distribution. While the Fed Funds Rate and Indian Call Money rate are positively skewed the Dollar Rupee exchange rate is negatively skewed. The Call Money rate and Fed Funds Rate are peaked distributions.

Step III

The stationarity test results of all the three returns series using Augmented Dickey Fuller test have also been reported in table 1 . It is evident the all the returns are stationary.

Table 1. Descriptive Statistics

\begin{tabular}{|l|l|l|l|}
\hline Statistic & $\begin{array}{l}\text { Fed Funds } \\
\text { Rate }\end{array}$ & $\begin{array}{l}\text { Exchange } \\
\text { Rate(rupee/dollar) }\end{array}$ & $\begin{array}{l}\text { Call Rate of } \\
\text { India }\end{array}$ \\
\hline Mean & -0.02 & 0.00065 & 0.0121 \\
\hline Median & 0 & 0.0013 & 0 \\
\hline Skewness & 1.27 & -0.261 & 2.40 \\
\hline Kurtosis & 4.65 & 0.11 & 16.41 \\
\hline $\begin{array}{l}\text { Standard } \\
\text { Deviation }\end{array}$ & 0.94 & 0.069 & 0.1394 \\
\hline ADF & -8.7429 & -7.8517 & -9.2473 \\
\hline
\end{tabular}

\section{Step IV}

The volatility of Fed Fund Rate, Exchange Rate and Call Rate derived from the MGARCH DCC model have been plotted against time as in Fig 1, 2, and 3 below.

From the Figure 1 below it is clear that the Fed Funds Rate was extremely volatile around the $52^{\text {nd }}$ date of the sample, ie end of June 2013. After that there was a steep fall in the volatility followed by gradually increasing volatility since mid July. Significant volatility clustering (periods of high volatility are followed by higher volatility and vice versa) is also evident throughout the sample period. 


\section{Plot of conditional volatilities and correlations}

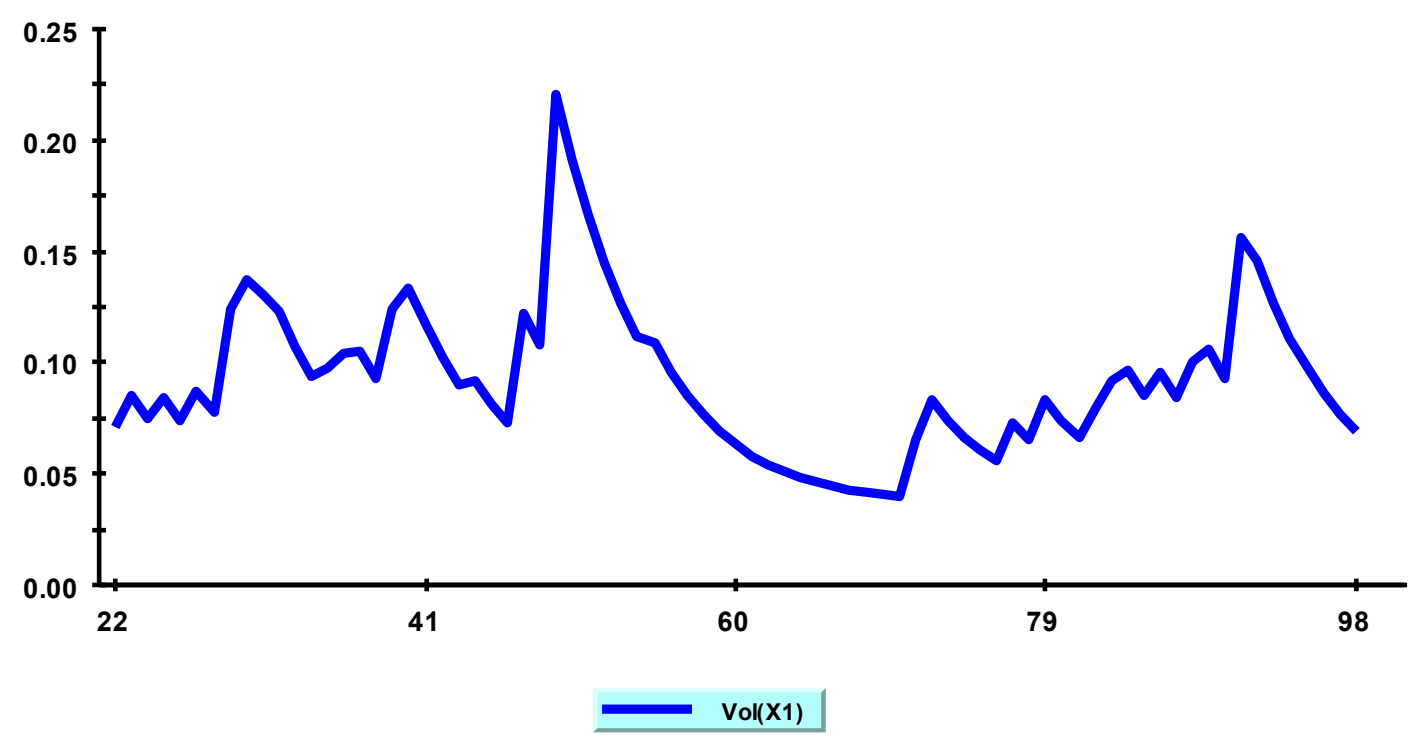

Figure 1 Conditional Volatilities of Fed Funds Rate $10^{\text {th }}$ may 2013 to $14^{\text {th }}$ Sept 2013

Plot of conditional volatilities and correlations

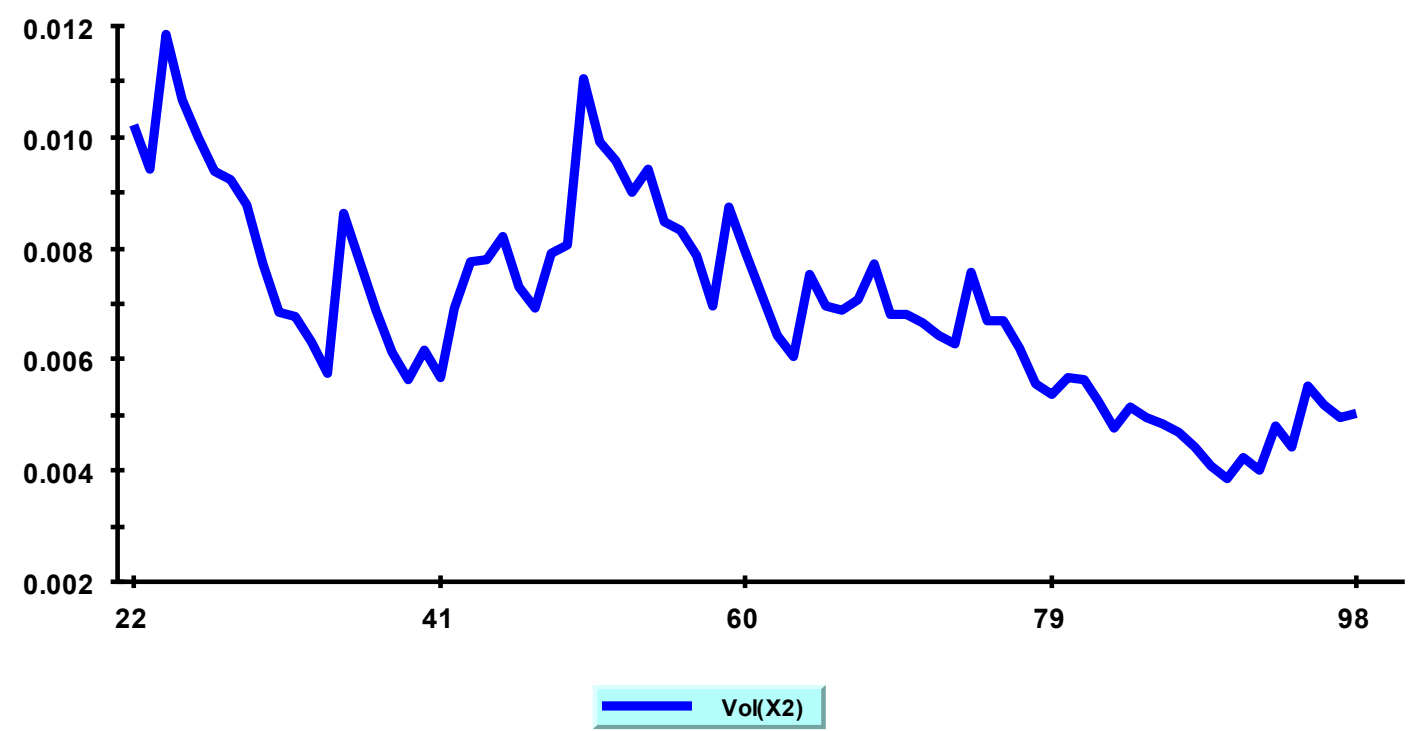

Figure 2. Conditional Volatilities of Rupee Dollar Exchange Rate $10^{\text {th }}$ may 2013 to $14^{\text {th }}$ Sept 2013

Similarly Figure 2 shows that the dollar rupee exchange rate volatility is almost identical to Fed Funds rate volatility. There was a sudden rise in volatility of the Dollar rupee exchange rate around the same period when the Fed Funds rate experienced high volatility. This clearly implies that the Dollar Rupee exchange rate responded to the information or news about the rollback of QE program in the US or alternatively, there was a volatility spill over from the Fed Funds Rate to the dollar rupee exchange rate. Volatility clustering is also evident in the series.

The volatility in the call rate is not identical to the fed rate and the exchange rate, however it is very clear that the call rate also started becoming volatile around the same period when the other two variables faced the peak of volatility in the sample period. The volatility then continued to increase subsequently and was at its peak towards the end of the sample period. Either there is a lag in the volatility spill over or some other factors are influencing the call rate volatility. A study of the Dynamic Conditional Correlations will give a clear idea of the extent of spill over from the Fed Funds Rate. Again volatility spill clustering is evident in call rates also. 


\section{Plot of conditional volatilities and correlations}

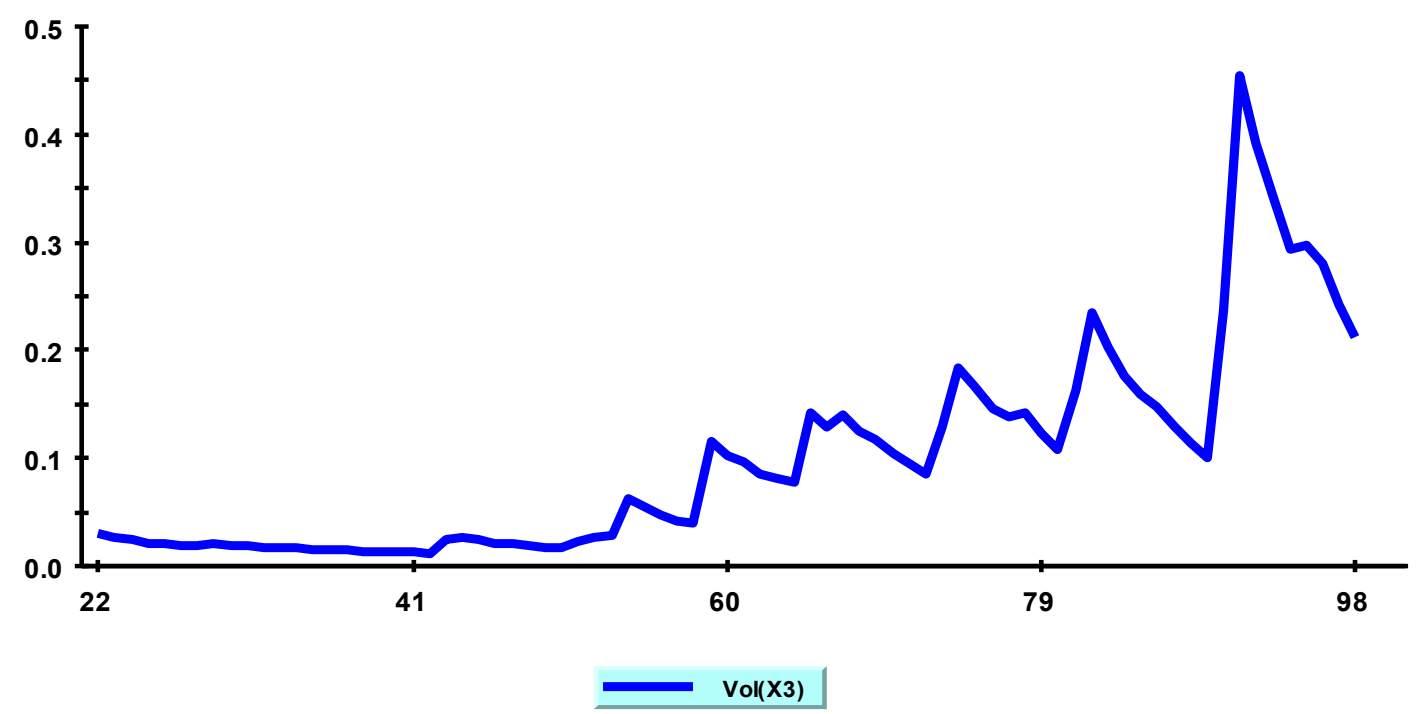

Figure 3. Conditional Volatilities of Call Money Rate $10^{\text {th }}$ may 2013 to $14^{\text {th }}$ Sept 2013

The Dynamic Conditional Correlations between the Fed Funds Rate and Rupee Dollar Exchange Rate, the Fed Funds Rate and the Call Money Rate and Rupee Dollar Exchange Rate and Call Money Rate have been estimated and plotted against time as in Figure 4, 5 and 6 respectively.

The Figure 4 below shows the DCC between the Fed Funds Rate and the Rupee Dollar exchange rates. It is clear that the DCC is negative almost throughout the sample period. Which implies an inverse relation between the two ie when the Fed Funds Rate falls the Rupee Dollar Exchange rate rises (ie depreciates) and vice versa. However, the spill over is asymmetric because the DCC is fluctuating very frequently. The DCC was maximum around the $50^{\text {th }}$ time period, ie around the end of June. This explains the high volatility in both the rates during the same period. Thus it is clear that the volatility in the exchange rate can be attributed to the volatility in the Fed Funds rate. It is also clear that the DCC became stagnant around -0.12 to -0.13 , for some time and then started falling above -0.1 after around end of July. The magnitude of the DCC between the two variables is around + or - of -0.1 during the sample period

Plot of conditional volatilities and correlations

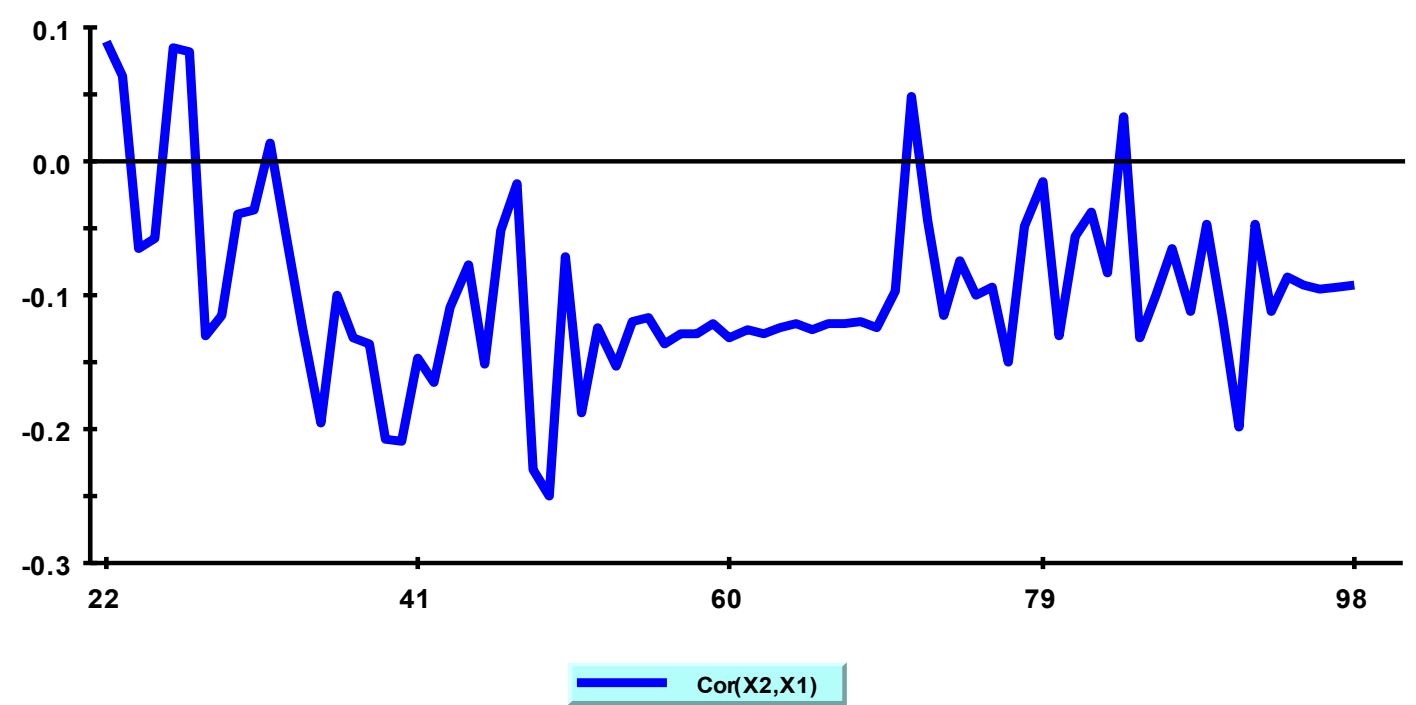

Figure 4. Dynamic Conditional Correlations of Fed Funds Rate and Rupee Dollar Exchange Rate $10^{\text {th }}$ may 2013 to $14^{\text {th }}$ Sept 2013 
The DCC between the Fed Funds Rate and the Call Rate is shown in figure 5 above. It is clear that the magnitude between the two is negative for a major part of the sample, and is less than that between the Fed Funds Rate and the Rupee Dollar Exchange Rate. This implies that the Fed Funds Rate brings about $2-3 \%$ variation in the call rate. It can also be said that the spill over comes after a lag of around 20 days. Again the volatility spillover is asymmetric.

\section{Plot of conditional volatilities and correlations}

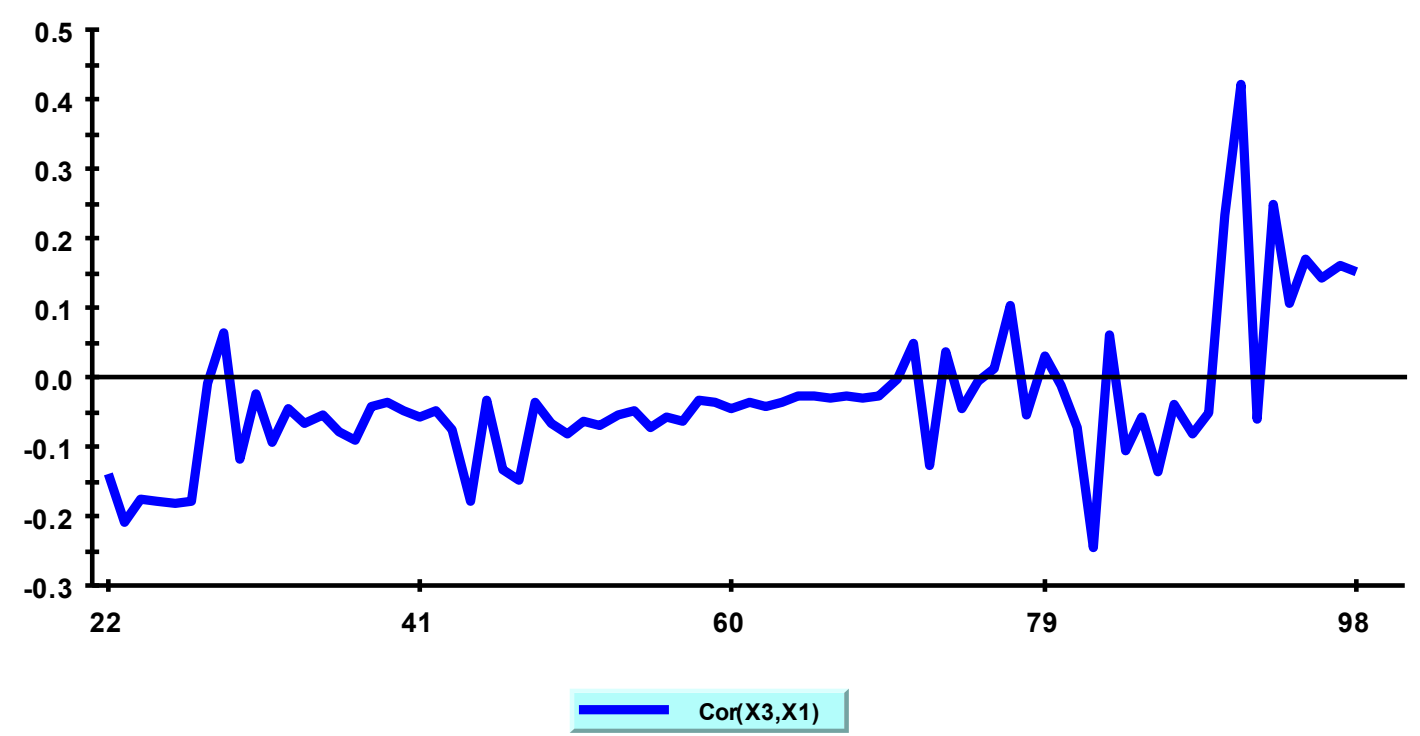

Figure 5. Dynamic Conditional Correlations of Fed Funds Rate and Call Money Rate $10^{\text {th }}$ may 2013 to $14^{\text {th }}$ Sept 2013

The Figure 6 below plots the DCC between the Dollar Rupee Exchange rate and the Call Money rate. Since both are asset prices of India the magnitude of DCC is higher and hovers around 0-0.1 to -0.4. The direction of spill over authenticates the theory. The fluctuations in the DCC is very high post the new on QE roll back by the US.

\section{Plot of conditional volatilities and correlations}

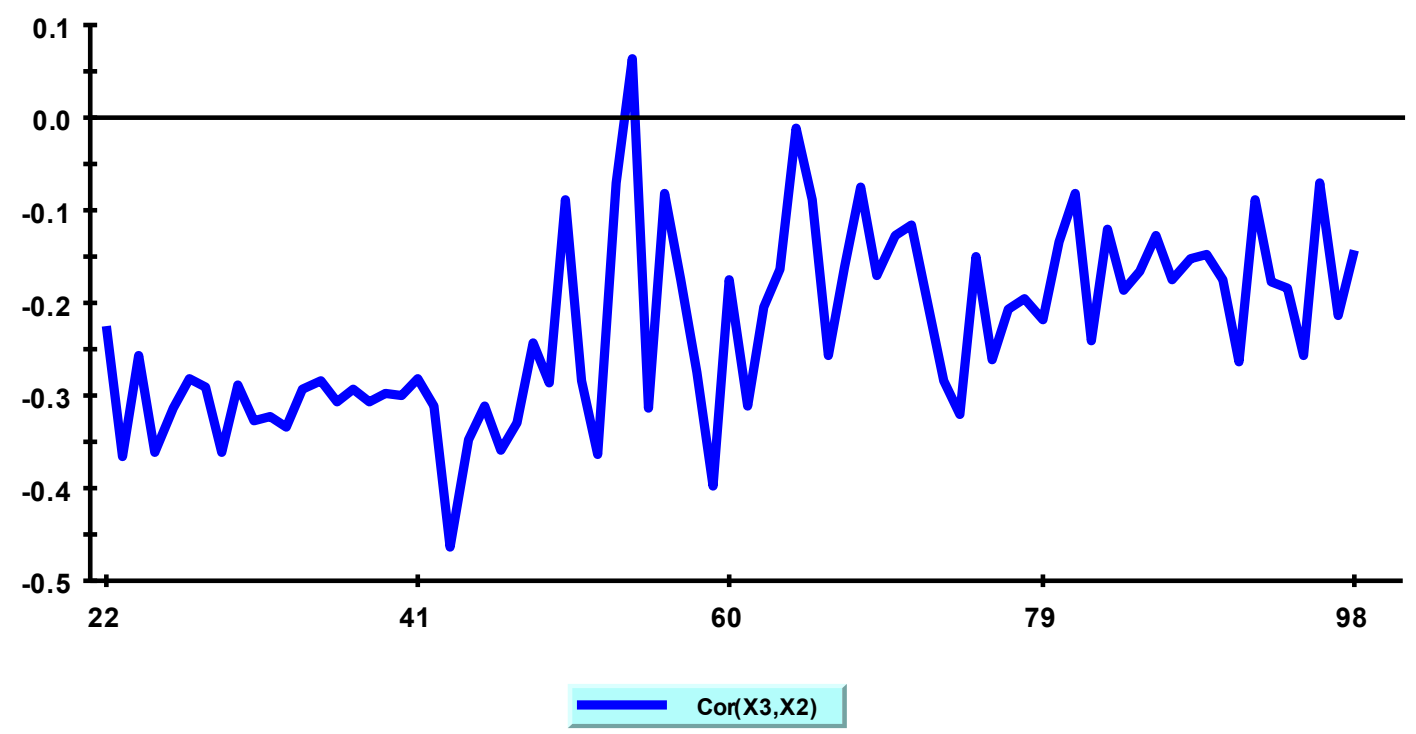

Figure 6. Dynamic Conditional Correlations of Rupee Dollar Exchange Rate and Call Money Rate $10^{\text {th }}$ may 2013 to $14^{\text {th }}$ Sept 2013 


\section{Step V}

The DCC MGARCH model was subjected to diagnostic testing. The results of the diagnostic tests are reported in table 2 below.

It is very clear from the table 2 that the LM statistic is insignificant. So we accept the Null that the $\mathrm{t}$ DCC model has been adequately estimated.

Table 2. LM Test (For Model Adequacy) Results

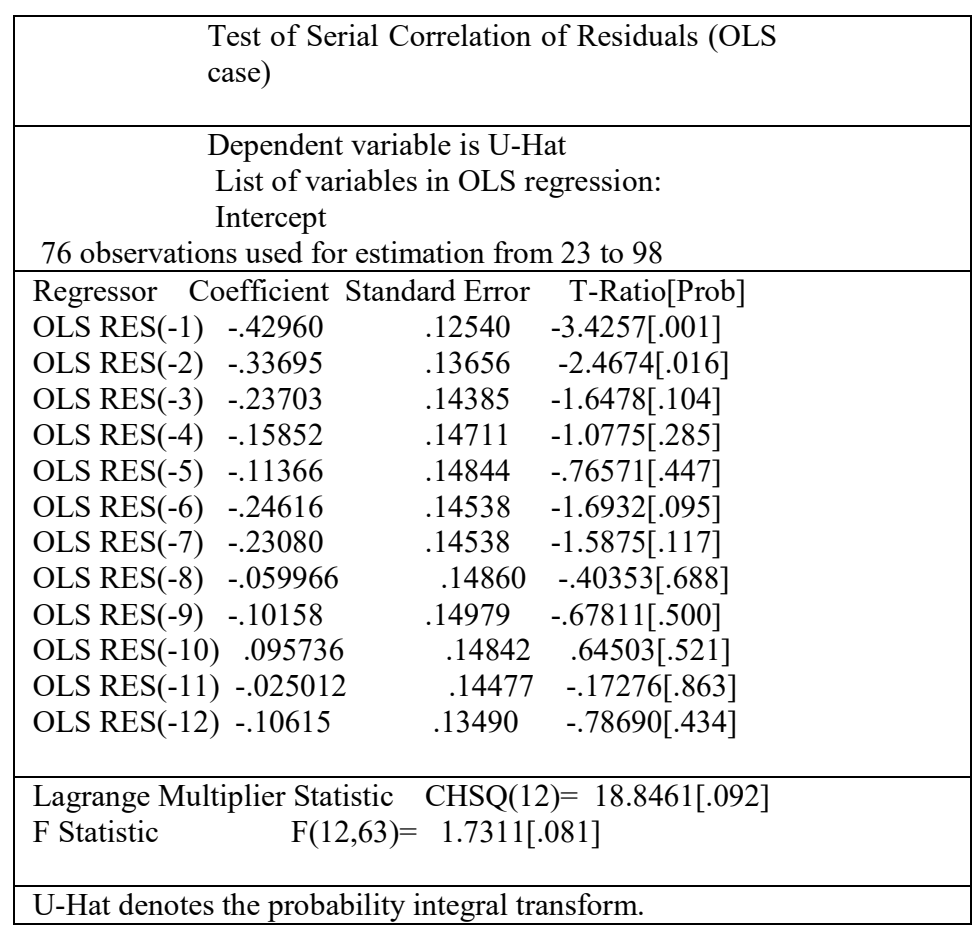

\section{CONCLUSIONS}

The results of empirical analysis clearly show that the volatility in Rupee Dollar Exchange Rates was majorly due to the US Monetary Policy. The spill over from the Fed Funds rate to the Rupee Dollar Exchange Rates was in a band of -0.1 to -0.2 , which could be treated as a $10-20$ percent impact and matches with the magnitude of depreciation of rupee during the sample period. Similarly spill over from the Fed Funds Rate to the Call Money Rate of India, has been found in the study. All this shows international transmission of volatility spillover into India. This also reflects the extent of India's integration with the US economy or to say when the US sneezes India also catches cold and that there is no decoupling.

In the light of the findings of the present study it can be said that the MANAGED float of Indian rupee should be managed properly. Similarly structural changes in the rules governing the capital flows into certain sectors (eg. the debt market) are imperative. It is also important that we should devise methods to reduce our excess dependence on short term capital inflows to finance the current account deficits. Giving a major boost to the manufacturing sector and making it export competitive can be one long term solution.

In conclusion it can be said that though the present study reflects the transmission of volatility into India from the US, it would have been more exhaustive if the spillover to the stock market were also included. 


\section{References}

[1] Alexander, C.O. (2000), "Orthogonal methods for generating large positive semidefinite covariance matrices. Discussion Papers in Finance 2000-06, ISMA Centre.

[2] Bautista, C. (2003), Stock market volatility in the Philippines, Applied Economics Letters, 10 (5), 315-318.

[3] Badrinath, H.R., Apte, P.G., (2005), "Volatility Spillovers Across Stock, Call Money And Foreign Exchange Markets, Unpublished, 1-26.

[4] Berkowitz (2001), "Testing Density Forecasts With Applications to Risk Management", Journal of Business and Economic Statistics, 21 79-109.

[5] Bollerslev, T., R.F. Engle and J.M. Wooldridge (1988), “A Capital Asset Pricing Model with Time-Varying Covariances”, Journal of Political Economy, 96, 116-131.

[6] Billio, M., Caporin, M., Gobbo, M(2006), Flexible dynamic conditional correlation multivariate GARCH models for asset allocation. Applied Financial Economics Letters 2, $123-130$

[7] Billio, M., M. Caporin and M. Gobbo (2003), "Block Dynamic Conditional Correlation Multivariate GARCH Models," Working Paper 03.03, Gruppi di Ricerca Economica Teorica e Applicata, Venice.

[8] Dijk, D., H. Munandar \& C. Hafner, (2011), "The euro introduction and noneuro currencies," Applied Financial Economics, vol. 21(1-2), 95-116.

[9] Engle, R. F. (2001), Dynamic conditional correlation: A simple class of multivariate GARCH models, University of California San Diego, Department of Economics.

[10] Engle and Kroner (1995), "Multivariate Simultaneous Generalised ARCH", Econometric Theory, Vol. 11, 122-150.

[11] Engle, Ng and Rothschild (1990), Asset Pricing with a Factor ARCH Covariance Structure: Empirical Estimates for Treasury Bills, Journal of Econometrics 45, 213-237

[12] Engle and Sheppard, 2001), Theoretical and empirical properties of dynamic conditional correlation multivariate GARCH, National Bureau Economic Research, working paper, No 8554.

[13] FRB of St. Louis website:- http://research.stlouisfed.org/fred2/data/DFF.txt.

[14] Hautschand and Inkman (2003), Optimal Hedging of the Currency Exchange Risk Exposure of Dynamically Balanced Strategic Asset Allocations . Journal of Asset Management, 4, 173189.

[15] Kearney, C. and V. Poti. (2003), DCC-GARCH Modelling of Market and Firm-Level Correlation Dynamics in the Dow Jones Eurostoxx50 Index." Paper submitted to the European Finance Association Conference, Edinburgh.

[16] Lee, M.C., J. S. Chiou and C.M. Lin (2006), A study of value-at-risk on portfolio in stock return using DCC multivariate GARCH, Applied Financial Economics Letter, 2, 183-188.

[17] Mishra, A. K., Swain, N and Malhotra, D.K., (2007) "Volatility Spillover between Stock and Foreign Exchange Markets: Indian Evidence", International Journal of Business 12(3), 343359.

[18] Mishra..A.K and Paul.T.,(2008), :-http://ssrn.com/abstract=1088255 or http://dx.doi.org/10.2139/ssrn.1088255 
[19] Pelagatti, Matteo M., and Setfania Rondena. (2004), Dynamic Conditional Correlation with Elliptical Distributions. Typescript

[20] Pesaran.B and M.H.Pesaran. (2007), Modelling Volatilities and Conditional Correlations in Future Markets with a Multivariate t Distribution, IZA DP No2905

[21] RBI Monthly Bulletins Various issues. 